Accepted, pre-published copy for University Repository

Richard Hetherington and Rachel McRae. Make-Believing Animated Films Featuring Digital Humans: A Qualitative Inquiry Using Online Sources. animation: an interdisciplinary journal Vol. 12, Issue 2, pp. xx-xx. Copyright $($ C 2017 (SAGE Publishing). Reprinted by permission of SAGE Publications.

Corresponding author:

Richard Hetherington, School of Computing, Edinburgh Napier University, 10 Colinton Road, EH10 5DT, UK.

Email: r.hetherington@napier.ac.uk

\title{
Make-Believing Animated Films Featuring Digital Humans: A Qualitative Inquiry Using Online Sources
}

\section{Richard Hetherington and Rachel McRae}

School of Computing, Edinburgh Napier University, UK 


\section{Abstract}

A qualitative inquiry of reviews of films featuring digital humanlike characters was performed by sampling user comments from three online reviewer aggregator sites: the Internet Movie Database, Rotten Tomatoes and Metacritic. The movies chosen for analysis were: Final Fantasy: The Spirits Within (2001), The Polar Express (2004), and Beowulf (2007), all produced using CGI animation, together with A Scanner Darkly (2006a) whose visuals are depicted by rotoscoping using Bob Sabiston's Rotoshop software. Our analysis identified individual differences in the viewing experience, particularly in relation to the uncertain ontology of the humanlike characters created using CGI (CGI-Humans). We found examples of reviews indicating an inability to

distinguish between real and CGI-Human actors, observations of characters transiently exhibiting realism before returning to their artifice, and of characters being viewed as eerie (analogous to the uncanny valley) thus illustrating a complex and dynamic response to this phenomenon. In some situations character uncanniness was related to the presence of an atypical feature such as movement of the eyes. Whilst specifically for Beowulf, perceptions became more problematic when there was familiarity with the actor playing the CGI-Human character, with some reviewers describing difficulties in categorising the character as either real or animated. CGI-Human performances were also characterised by a lack of, or inappropriate social interaction. Online reviewers did not perceive characters depicted using Rotoshop (Rotoshop-Humans) as eerie and rotoscoping was found to preserve, and possibly enhance, the natural social interactions between actors recorded from the live-action film used as the source for the animation. Our inquiry also identified user motivations for viewing these movies and the importance placed by reviewers on the form of display when viewing the CGI films. We situate our interpretation of these findings in relation to Walton's make-believe theory (Mimesis as Make-Believe: On the Foundations of the Representational Arts, 1990) revealing its application to our understanding of the viewing experience of animated films featuring digital humans.

\section{Keywords}

Make-believe, digital humanlike characters, CGI, Rotoshop, uncanny valley, viewer experience. 


\section{Introduction}

In this article we differentiate between two distinct processes used to create digital humans in animated movies: In the first, characters were created using 3D computergenerated imagery (CGI) and animation techniques including motion or performance capture (mocap). Such characters feature in works that are intended to be perceptually realistic (Prince, 1996) and have been referred to as 'hyper realistic' (McClean, 2007), 'synthespians' (Aldred, 2011), or simply - CGI characters (Sobchack, 2006); and are featured in movies including: Final Fantasy: The Spirits Within (2001), The Polar Express (2004) and Beowulf (2007). We shall refer to these characters as 'CGI-Humans'. In the second process, humanlike characters were created by a digital implementation of rotoscoping - a technique whereby animators create an animated film by drawing frameby-frame over a live-action source. The film we examined was A Scanner Darkly (2006a), which was created using the Rotoshop software developed by Bob Sabiston (Flat Black Films, n.d.) and we use the prefix 'Rotoshop-' or 'Rotoshopped-' to refer to digital humans depicted by this process. Though all of these films are positioned towards realism, the outcomes produced from CGI techniques and Rotoshop are aesthetically distinct from each other and have been the subject of much academic research and critical review, with attention frequently directed toward the uncertain ontological nature of the digital humans featured (e.g. Aldred, 2011; Sobchack, 2006; Plantec, 2007; Ruddell, 2011; Honess Roe, 2011; Hetherington, 2015; Kätsyri, Mäkäräinen, and Takala, 2017).

A common experience when viewing the CGI films mentioned above is the eerie or uncanny nature of the CGI-humans they feature. These characterstics have been variously described as 'lifeless', 'creepy', 'eerie' and 'zombie-like' (Aldred, 2011; Plantec, 2007; Hetherington, 2015; Kätsyri, Mäkäräinen, and Takala, 2017); and as such are considered to occupy the 'uncanny valley' - a situation described by Mori ${ }^{1}$ (1970) where near humanlike artefacts (e.g. a humanoid robot, bunraku puppet, prosthetic hand) prompt strong negative reactions in an observer (MacDorman and Entezari, 2015). A preliminary study revealed some viewers perceived the Rotoshopped Bob Arctor character in A Scanner Darkly also to be eerie (Hetherington, 2015). Honess Roe (2011: 31) describes the talking-head interviews created with Rotoshop by Bob Sabiston as 'an uncanny sense of reality haunting the animated image'. However, it remains unknown how generalisable the experience of characters being uncanny is when considering the reception of these films by viewing audiences. MacDorman and Entezari (2015) have reported individual differences in the perception of videos of androids exhibiting varying levels of human likeness and eeriness, concluding that sensitivity to the uncanny valley is associated with sociocultural constructions and biological adaptations related to threat avoidance. It seems clear that we cannot confidently extrapolate individual critical analyses of these movies to the wider viewing audience. In addition, the uncanny nature of these characters appears likely to form only part of the overall viewing experience. When asked to consider another dimension of the viewing experience of humanlike characters - their believability - participants identified a number of influences operating within and also beyond their direct experience of the character in the film, including references made to technical aspects of character creation and animation, the visual integration of the characters within their background and their interaction with props, 
previous experience of playing video games, narrative expectations, and familiarity of the actor connected with the animated character's performance (Hetherington, 2015). These observations motivated us to conduct the present study in order to gain a wider understanding of viewer responses to films featuring digital humans.

The Internet has become an increasingly important means to support the understanding of media. Cresswell (2013) has discussed the pros and cons of qualitative data collection via the Internet: Problems include ethical issues over privacy, ownership and use of data, establishing the authenticity of data, and the requirement for participants to have computing skills. Potential advantages include: cost and time efficiency, a more amenable environment for data generation and collection, and ease of accessibility to target groups and in providing data. Successful examples of use include using social media to recruit participants and interview them using Internet video chat for a qualitative inquiry of player-avatar relationships (Banks, 2015), and the analysis of online collaborative discourse generated by fans of progressive rock music (Atton, 2012). In this article we use openly available online film review aggregator sites as a source of qualitative data for our inquiry.

Three review aggregators were chosen as data sources for our qualitative inquiry: The Internet Movie Database (IMDb, www.imdb.com), Rotten Tomatoes (www.rottentomatoes.com) and Metacritic (www.metacritic.com). All sites publish ratings and reviews of movies submitted by users and critics and typically receive 8 to 200 million unique monthly visitors (IMDb, 2016; Quantcast, 2016; trafficestimate.com, 2016). All the sites claimed to implement moderation and consistency checks by staff and reviewers to ensure reliability and accuracy of information. The distinction made between critic and user reviews on these sites prompted us to consider what would be the most appropriate sampling strategy for the present study. Differences in ratings between critics and users have been noted with critics showing greater variability and harshness in their judgments (Follows, 2014). An analysis of the content of online film reviews by professional critics or consumers found consumers to predominantly evaluate the films and write from a personal perspective, whereas reviews written by critics described the film instead of evaluating it (de Jong and Burgers, 2013). Film critic Todd McCarthy notes that reviews written by online pundits who aren't recognised film critics are becoming increasingly prominent and influential (McCarthy, 2007). A film evaluation study by Chakravarty, Liu and Mazumdar (2010) comparing the impact of online user comments with reviews by film critics revealed infrequent filmgoers to be more influenced by user reviews, while frequent filmgoers were more influenced by the reviews written by the critics. As the aim of our study was to collect information to help us understand how viewers experience films we concluded that the more useful source of experiential information would be online user comments.

We have chosen to situate our interpretation of user comments of these films in relation to the characters' believability - a recognised objective of many animated films including those examined here. In order to engage with animated works the audience is often assumed to 'suspend their disbelief' i.e. to make-believe. Kendall Walton's theory of make-believe (Walton, 1990), also known as pretend theory, proposes that representational artworks including paintings, plays, novels and movies serve as 'props' 
which prescribe specific imaginings and are analogous to the role toys serve in children's games, enabling entry into a fictional world ${ }^{3}$. Recently, Bateman (2010 and 2011) has applied make-believe theory to engagement with games and videogames. However, to our knowledge, animated movies per se have not been examined even though believability is an important quality of the viewing experience. In view of the reported eerie nature of the characters, we contend that the films chosen in this study make interesting candidates to examine make-believe and its possible limitations.

\section{Qualitative Inquiry}

Random samples of 25 user reviews were taken from each of three online reviewer aggregator sites (IMDb, Rotten Tomatoes and Metacritic) for three CGI films (Final Fantasy: The Spirits Within, The Polar Express and Beowulf) and a film animated by interpolated rotoscoping using Rotoshop (A Scanner Darkly). At this stage, determining a sample's demography for IMDb was problematic due to the cryptic nature of many usernames making it impossible to accurately determine reviewer gender. This was less of a problem for the other two sites as user profiles typically contained a first name and often a photograph of the reviewer. Using only unambiguous reviewer usernames revealed a male to female ratio of around three to one $(n=248)$. If we were to assume that site visitor demographics reflected those of reviewers, data for Rotten Tomatoes indicate a male to female ratio of 2.6:1 with the majority of visitors being in age groups of 18-24yrs and 25-34yrs (Quantcast, 2016). Another issue we encountered was only being able to access the more recent user comments posted from Rotten Tomatoes.

Movie viewing information was garnered by a thematic analysis assisted by computer software (NVivo10, QSR International). The analysis involved induction, interpretation and iteration of data in order to identify relevant themes, bracketing ${ }^{2}$ any prior knowledge from articles read and our own viewing experiences of these films. Only data considered relevant to the description of the viewing experience were included in our analysis, which proceeded by identifying individual coded references. A coded reference represents a discrete thought or observation and may take the form of a phrase, sentence, or paragraph in a review - a 'unit of meaning'. These thoughts are captured and aggregated through the process of coding into categories of information (codes) that were allowed to emerge naturally and from which themes were identified and developed. Coding was done by repeatedly reading film reviews to give an initial set of coding categories, which after several reflexive iterations were re-structured into a working set of 14 main categories covering comments relating to: actors and acting, aspects of production, character, writing, believability, interpretation; and other aspects of the viewing experience including time and location of viewing, emotional response, memorability, immersion, atmosphere and mood. Several main categories were differentiated into sub-categories. For example, an 'aspects of production' category was broken down into recognised elements of production including: cinematography, effects, animation, sound design; 'actors and acting' was subdivided into comments relating to performance, the cast, and comments relating to real versus computer-generated actors. The 'character' category contained a diverse range of comments which were broken down into 10 sub-categories including: visual appearance, relationship to other 
characters, movement, voice, perceived depth and development, portrayal of emotions, and interaction with the environment and props. Any unit of meaning belonging to more than one category or sub-category was coded to all relevant categories or sub-categories. When the coding system was considered stable, inter-rater reliability was tested for a random sample of five reviews from each movie $(n=20)$ coded independently by two researchers. The percentage agreement was $98 \%$ and the value of Cohen's kappa coefficient was 0.77 indicating a substantial level of agreement and reliability for the coding process (Landis \& Koch, 1977).

Reviews sampled for each movie varied considerably in quality and length. In some cases there were few words of relevance to the study, whilst in others several paragraphs of relevant discourse were found. Meaningful data were recovered from all the review aggregator sites, the IMDb being the most prolific source, and on completion of the process around 500-600 coded references were obtained for each film in total. In situations where data is collected through participant interviews (for example in phenomenological research), interviewing typically continues until a point of information saturation has been reached. In our study, the order of analysis of the databases was randomly determined as: IMDb, Rotten Tomatoes and Metacritic and by retrospective examination we suggest an equivalent point had been reached after data gathering from the first two databases had been completed (the order of analysis being a significant factor in this estimate). Further analysis of coded references often led to the identification of higher-level themes frequently informed by data clustered from different coded categories. Those themes considered relevant to the viewing experience were: how films were viewed, reviewer expectations, individual differences, character perceptions and actor-character relationships. An example of the relationship between an identified theme, its related categories and sub-categories and corresponding reviewer data is shown in Table 1. 
Table 1. Selected example of an identified theme, its related categories and subcategories and corresponding data.

\begin{tabular}{|c|c|c|}
\hline Theme & $\begin{array}{l}\text { Code category: sub- } \\
\text { category }\end{array}$ & Reviewer comment excerpts \\
\hline \multirow[t]{6}{*}{$\begin{array}{l}\text { 'Character } \\
\text { perception' }\end{array}$} & Character: Appearance & $\begin{array}{l}\text { 'Unfortunately, the CG characters were not quite } \\
\text { realistic enough, and looked like zombies' - } \\
\text { 'FranzH', (2015) }\end{array}$ \\
\hline & \multirow[t]{2}{*}{$\begin{array}{l}\text { Character: Character } \\
\text { relationships }\end{array}$} & $\begin{array}{l}\text { 'the eyes of the characters often seem to 'stare } \\
\text { into space' rather than effectuating eye contact } \\
\text { with one another' - 'Eternality', (2011) }\end{array}$ \\
\hline & & $\begin{array}{l}\text { 'When the heroes, Grey and Aki, finally kiss, it's } \\
\text { almost pornographic in its lack of emotional } \\
\text { commitment' - 'awjonesjr', (2001) }\end{array}$ \\
\hline & \multirow[t]{2}{*}{$\begin{array}{l}\text { Acting and actors: Actors - } \\
\text { real versus computer- } \\
\text { created }\end{array}$} & $\begin{array}{l}\text { '...the motion captured animations that are used } \\
\text { in many of the action sequences are great and at } \\
\text { times are so life like you are fooled and for a } \\
\text { second here and there and it looks as if it is a real } \\
\text { actor running' - 'joltjohn', }(2002)\end{array}$ \\
\hline & & $\begin{array}{l}\text { 'This is a groundbreaking milestone in the } \\
\text { history of animation and it answers a question as } \\
\text { old as time: Can we really animate realistic } \\
\text { human beings? The answer is, I am happy to } \\
\text { report, yes' - 'crowrobot', (2005) }\end{array}$ \\
\hline & $\begin{array}{l}\text { Acting and actors: } \\
\text { Performance }\end{array}$ & $\begin{array}{l}\text { 'For me the most disappointing part of the film } \\
\text { was actually Ray Winstone as the titular } \\
\text { character - he was fantastic when talking in a } \\
\text { low growl, however the film really suffers when } \\
\text { he shouts in full cockney accent. "I will kill your } \\
\text { monstah!"'- 'cdemw', (2007) }\end{array}$ \\
\hline
\end{tabular}




\section{Make-believe and the viewing experience}

\section{Background Propositions and Principles of Generation}

Make-believe can be viewed as exchanging one worldview with an alternative whilst still being aware of this substitution, which makes it useful to consider what brought viewers to voluntarily engage in the fictional world of the animated film. The reviews sampled presumably originate from individuals motivated to engage in the fictional worlds of these films for various reasons, and an examination of these motivations or expectations may inform our understanding of the viewing experience.

Reviews revealed viewer expectations came from prior knowledge of either the reputation of director or actors, or of interest in the technology used to create the movie (e.g. CGI, motion capture), or of the prospect of seeing a new representation of the story. The narratives in the featured movies originated from or were inspired by an earlier source, such as a novel, epic poem, or videogame. So through intertextuality, prior knowledge may serve as a 'scaffolding' to support make-believe in the fictional animated world. Walton's theory of make-believe (Walton, 1990) refers to 'background propositions' imported by the viewer to enhance the fictional world, making it easier to imagine and participate in. The importance of such propositions is illustrated by comments of A Scanner Darkly where some reviewers noted challenges engaging with the story. 'Reviewer_A' (2011) wrote: 'This film is a jigsaw puzzle. It's certainly not for everyone, and it requires patience and possibly repeat viewings in order to be fully understood and enjoyed'. Some reviews criticised the clarity and pacing of the plot, with cases of disengagement from the film due to boredom. While other reviewers familiar with the original novel praised its representation in animated form, commenting on the appropriateness of its depiction through rotoscoping.

As a film inspired from a videogame, the anticipated release of Final Fantasy: The Spirits Within seems to have raised expectations from gaming fans that the film would reflect the stories encountered in the videogame. The outcome was commonly disappointment. 'Reviewer_B' (2001) wrote: 'Fans of the videogame series will be disappointed to see this film has very little in common with any plot from the games, nor does its world fit with the Final Fantasy cosmos.' Another fan elaborated: '... I learned a painful fact: the movie was to be set on Earth, a Final Fantasy no-no as any die hard fan will tell you' ('Reviewer C', 2001). Reviewers not having prior knowledge of the videogame tended to regard the film's story more favourably. Similar condemnations of how the original story had been represented were found for some of the other movies. In the case of The Polar Express the extension of the plot from the original book in order to produce a feature length film was criticised ('theshadow908', 2006). While for Beowulf, 'cinderellakt' (2008) stated her disgust at the terrible job that was done in 'conveying the real meaning of the poem'. Walton (1990) contends that what is prescribed to be imagined by a prop (in this case the animated film) is governed by certain conventions, understandings or agreements termed 'principles of generation' of which there are two: The reality principle is based on similarities to the real world, while for fantastic worlds the mutual belief principle applies and is based on a tacit agreement between the creator 
of such worlds and those who engage in them. The films examined here are to varying extents fantastical and importing 'narrative scaffolding' into the viewing experience; this may be an important factor in establishing make-believe for A Scanner Darkly. For Final Fantasy: The Spirits Within, The Polar Express and Beowulf many viewers appeared to have this scaffolding in place from either playing the video game or reading the relevant text, but on viewing the movies were often disappointed when their expectations, particularly in relation to the story, weren't met suggesting that the mutual belief principle was compromised.

\section{Depiction}

Knowledge of how a phenomenon is experienced forms an important part of the overall understanding of it. Comments made by many reviewers included information relating to the media used to view the movies, which included DVD, television, and various forms of cinema viewing. The need to attend a cinema viewing was highlighted in reviews specifically for the CGI movies, which at the time represented the technological state-ofthe-art in use of production and display technologies. Final Fantasy: The Spirits Within was released in 2001 and online reviewers praised the visual spectacle created. Movie critic Roger Ebert described the look of the film as 'revolutionary' (Ebert, 2001). The Polar Express and Beowulf were both directed by Robert Zemeckis - an enthusiastic early adopter and developer of digital technologies, most notably mocap (Bestor, 2016). This enthusiasm was also evident by the director's choice to render Beowulf and The Polar Express in IMAX (Image Maximum - a high resolution, large-frame format requiring specialist capture and display technologies) IMAX-3D and 3D cinema formats:

...it was a pleasure to view the film [Beowulf] in IMAX-3D. Zemeckis utilizes the technology well, giving us moments of true depth. Whether flying through the tree branches, having a spear frozen in front of our eyes, watching bodies fall and flip towards us, and seeing blood splattered in our faces, we are thrown smack dab in the middle of the action. ('jaredmobarak', 2007)

'Robert D' compared his viewing of Beowulf to 'a rollercoaster ride, I was jumping, and moving with the camera' ('Robert D', 2009). In make-believe theory, Walton identifies two ways in which representations can be created: they could be perceptual in nature invoking one or more of our senses and are considered as depictions, or as verbal representations as in the case of novels and are mainly narrative in nature. Walton (1990) defines depiction as 'a representation whose function is to serve as a prop in reasonably rich and vivid perceptual games of make-believe', referring to representations where it is relatively straightforward for a viewer to deduce that what they are looking at is the intended representation. Consequently, the additional depth cues, wrap-around vision, and improved visual and aural fidelity provided by IMAX, IMAX-3D and 3D cinema suggest these modes of presentation could act as more effective depictive props into the film's fictional world, as well as providing added spectacle. This situation doesn't hold with all viewers however: For Beowulf, one reviewer expressed concern that this mode of presentation may overburden their experience and impede them in engaging with the story and its themes ('AaronN', 2007). In another case a reviewer points out: '...the big problem I had was that the movie tried too hard to make the audience remember it's in 
3D' ('The_Amazing_Spy_Rises', 2007). A preoccupation with the medium, particularly the medium chosen for viewing was a characteristic of reviews of the three CGI movies, the previous examples describing highly embodied experiences. The enhanced visual and aural stimuli provided in IMAX-3D possibly contributing to a greater sense of presence by placing the viewer more in the diegetic world.

\section{The Uncertain Nature of Digital Humans}

Online reviews revealed some viewers to express confusion and uncertainty about the ontology of the CGI-Human characters. One feature of this being the perceived eeriness of characters which is consistent with them occupying the uncanny valley (see MacDorman and Entezari, 2015). Some reviewers directly referenced the uncanny valley $^{4}$, but it was more common to find reviewer descriptions consistent with this phenomenon. 'FranzH' provides a suitable encapsulation: 'Unfortunately, the CG characters were not quite realistic enough, and looked like zombies. I spent too much time noticing how creepy they all looked' ('FranzH', 2015). This comment was directed towards Beowulf, but similar observations were found in the other CGI movies, with characters being variously described as 'animated dead people', 'zombie-like', 'ghoulish', 'mummified' and 'doll-like'; which are consistent with several studies (e.g. Aldred, 2011; Sobchack, 2006; Plantec, 2007; Hetherington, 2015; Kätsyri, Mäkäräinen \& Takala, 2017). As noted in earlier work, features contributing to a character's uncanniness predominantly related to facial animation, in particular the character's mouth and hair movements in Final Fantasy: The Spirits Within, and the eyes for Beowulf (see Figure 1):

There's a jarring problem though - the eyes of the characters often seem to 'stare into space' rather than effectuating eye contact with one another; it's the main reason there's low chemistry among the characters, and also why we feel the presence of a vacuum between viewer and character. ('Eternality', 2011)

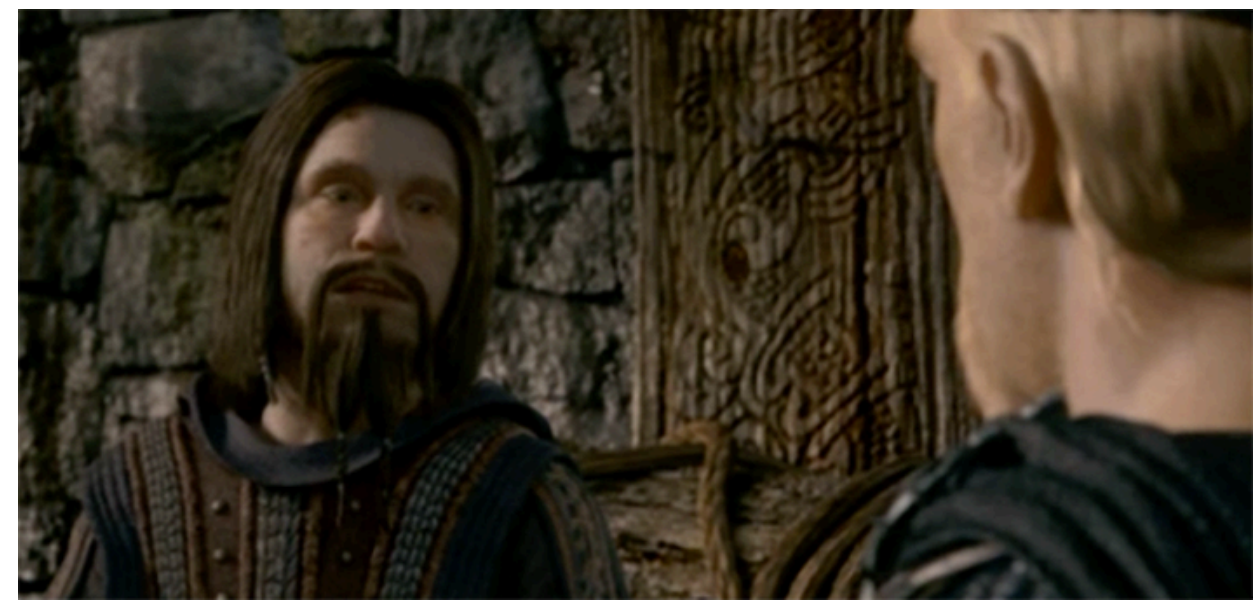

Figure 1. Example of 'staring' character appearance: 'Unferth' played by John Malkovich in Beowulf (2007). Screen grab from DVD [Beowulf, Robert Zemeckis]. 
'Eternality' (2011) makes the connection between this deficiency and its impact on the social interaction between characters. In a related instance for Final Fantasy: The Spirits Within the misinterpretation of social interaction produced a confused message:

The computer technology can reproduce the mechanics of acting, but not the ineffable qualities that make you care about the characters. When the heroes, Grey and Aki, finally kiss, it's almost pornographic in its lack of emotional commitment -- rather like sculptures being molested by puppets ('awjonesjr', 2001).

The CGI-Humans featured are part of a group of stimuli, all related by their human likeness which is able to elicit an uncanny experience, the result often being some form of aversion. However beyond this, what characterises the feeling that something is uncanny is 'left unspecified by the experience itself' (Mangan, 2015). In his 1906 essay, Jentsch concludes the uncanny arises from 'intellectual uncertainty' and refers to the uncertainty in terms of whether an apparently living being is animate or not, or whether a lifeless object may in fact be alive. He continues to suggest ways in which the uncanny can be achieved including interpreting a lifeless thing anthropomorphically as part of an organic creature - 'a rafter covered in nails becomes the jaw of a fabulous animal... the outline of a cloud or shadow becomes a threatening satanic face' (Jentsch, 1906/1997) descriptions similar to those encountered in childhood pretence in make-believe games.

Freud concluded the uncanny as being something familiar (Heimlich) while at the same time unfamiliar (Unheimlich) (Freud, 1919/2003). A viewer observing a character that is both familiar and unfamiliar may be simultaneously attracted and repulsed, and may experience cognitive dissonance (Festinger, 1957) which could lead to outright rejection and disengagement from the experience. Plantec (2007) has proposed cognitive dissonance to account for the uncanniness of the CGI-Human characters found in the films examined here. The uncanny valley has also been examined empirically, with a review of relevant studies revealing two main groups of theories to explain it: category uncertainty and perceptual mismatch (Kätsyri et al, 2015). Category uncertainty theories propose uncanniness is caused by doubt about what an entity is. The theories of Jentsch (1906/1997), Freud (1919/2003) and reports of cognitive dissonance belong to this category. Perceptual mismatch theories relate uncanniness to a feature of an entity being atypical including disparities between specific visual, aural and motion character traits, for example reports about the eyes for the Beowulf characters.

However, it should be noted that uncanny experiences were described in less than a quarter of reviews sampled and significantly there were a number of instances, particularly for Final Fantasy: The Spirits Within, where comments revealed reviewers believed they were watching a real as opposed to an animated character:

This is a groundbreaking milestone in the history of animation and it answers a question as old as time: Can we really animate realistic human beings? The answer is, I am happy to report, yes..... During some scenes, I was thoroughly and utterly convinced I was watching a "real" movie ('crowrobot', 2005). 
Other reviewers noted a transient aspect of this experience where their perception of a character appeared to fluctuate between that of a real and a CGI-Human actor:

...the motion captured animations that are used in many of the action sequences are great and at times are so life like you are fooled and for a second here and there and it looks as if it is a real actor running around in armor and not a creation of an artist ('joltjohn', 2002).

It appears character uncanniness may form a significant part of the overall viewing experience for some viewers and be entirely absent for others, or a transient state exists in perception between the real and the animated. We consider these observations of inconsistencies in perceiving characters as real or animated to be an important part of the audience experience, and the above comments may help to explain findings of greater variability in viewer ratings of uncanniness and believability of these characters (Hetherington, 2015).

In comparison to CGI-Humans, reviewers reported a different experience of Rotoshopped characters in A Scanner Darkly. References to creepy or eerie characters were absent, leading us to question whether character uncanniness is a recognised experience when viewing this film. An earlier study revealed that when participants were asked to rate the eeriness of protagonists in films featured here, the Rotoshopped character of Bob Arctor was rated as more eerie than any of the CGI-Humans. Analysis of comments made suggested the unease may be due to the way in which the character's skin and beard kept moving and changing shape of their face (Hetherington, 2015). A prescribed style guide was followed by animators in A Scanner Darkly, including instructions of how character facial features were to be rendered (A Scanner Darkly, 2006b), the result being a painterly aesthetic (Ward, 2011) closely resembling a graphic novel (Materna, 2006). A comparative functional magnetic resonance imaging (fMRI) study of a related film Waking Life (2001), with its live-action source, found that in the Rotoshopped film, viewers found it harder to detect intentionality of characters, but found the films more rewarding to view (Mar et al., 2007). In her aesthetic analysis of the visual style of Waking Life and A Scanner Darkly, Ruddell draws attention to the dynamic relationship between the animated line and the live-action footage it is based upon, which seems to create a categorical uncertainty in the viewer as to whether these films should be regarded as live-action or animation (Ruddell, 2011); this may help to explain any perceived eeriness of the characters. Honess Roe describes Rotoshop animation as an 'aesthetically liminal style' creating 'a pleasurably complex and challenging epistemological and phenomenological viewing experience' (Honess Roe, 2011: 25). Within the context of $A$ Scanner Darkly, online reviewers often considered their feelings of strangeness and creepiness as an appropriate representation of the fictional world as intended by the novel's author Philip K. Dick ${ }^{5}$. The visual style of Rotoshopped characters is less photorealistic than the highly textured and complexly shaded CGIHumans. Using modified sets of isolated static CGI faces MacDorman et al (2009) found that the closer to photorealism facial surface textures became the more humanlike they were perceived to be, with the consequence of this increased fidelity being a heightened sensitivity to uncanny facial features. Consequently, the more stylistic look of Rotoshopped characters may operate in their favour by being less likely to induce eerie feelings in viewers. 


\section{Actor-Character Relationships}

A review of Keanu Reeves' performance as the protagonist in A Scanner Darkly noted: 'Maybe it's the rotoscoping, but here he delivers a touching and moving performance, something of the conflicted hero, a damaged and flawed presence, a complexity I didn't think I'd see from this actor' ('Dribbleglass', 2007). Another reviewer continues:

The acting is superb from all the cast, but Robert Downey Jr.'s performance stands out as the best by far. The animation style adds to the surreal atmosphere and matches the disturbing dystopian setting perfectly. It is done in such a way that it doesn't detract from the story or any actor's performance at all, ...('Reviewer_A', 2011).

A similar depth and quality in acting was found in situations where there was interplay between the main characters. 'legendarydrunkenmaster', (2009) wrote:

Truly amazing. I love the banter between Robert Downey Jr and Woody Harrelson, pure comic genius. I love all the little subtle things I missed the first time around and how almost everything had meaning

Taken collectively, the above comments reveal that the depth of character performance, both individually and socially, captured in the live-action source movie, was preserved and possibly even enhanced by Rotoshop. The quality of social interaction observed between characters in this situation is in sharp contrast with that described previously for the 'intimate' scene in Final Fantasy: The Spirits Within. Furthermore, in contrast to A Scanner Darkly, the presence of recognisable actors playing CGI-Human characters in Beowulf often created a negative viewing experience with the viewers' familiarity of the actor in the character creating another dimension of eeriness:

It is a very strange sensation to watch a film where the cast comprises largely imitations of the people in the cast: watching Anthony Hopkins occupy a replica of himself is profoundly weird. The experience then becomes even weirder when the character inhabited by the larger than life persona of Ray Winstone isn't Winstone! ('Neil Welch', 2009).

Inconsistencies in the visual representation between different actors and the character they played was found to be disconcerting, further compromising their believability:

...this search for realism brings to the spotlight a major problem: the quality of the animation doesn't look constant, as while some characters do look amazingly like the actors that play them (Grendel's mother being the most notorious), others look extremely fake (Wiglaf and Hrothgar for example), so the contrast between them is glaringly obvious, and that's really bad ('jluis1984', 2007).

Beowulf seems to have been particularly problematic with regard to the acceptance of characters. One reviewer reflected upon not recognising some of the main actors (Anthony Hopkins and John Malkovich) while another commented: 'why did Ms. Robin Wright's eyes look so distorted? .... this movie distorted her appearance so much that it detracted from the story line ('Mary P', 2014). Another reviewer went further: 
I almost wish all the characters were devoid of any likenesses to their reallife counterparts like our lead. It is just too distracting, leading my mind to wander and think of how the cgi person differs from the actor. This is especially true with John Malkovich's Unferth. They try to make him different enough, but the face is still there ('jaredmobarak', 2007).

Plantec reports a similar case for characters Tom Hanks played in The Polar Express, suggesting this familiarity intensifies the uncanny valley situation (Plantec, 2007). Returning to theories of the uncanny valley, the above examples reveal some viewers appearing to have an uncertainty in categorising these digital humans: the actor playing the character is familiar, yet is somehow unfamiliar creating cognitive dissonance with the potential of experiencing an emotional state of discomfort and unease the viewer may be motivated to reduce (Elliot and Devine, 1994). As the causal factor of this dissonance is perceptual in nature, one possible way of reconciling the situation is through rejection or avoidance of the situation causing it as was found for this review of Beowulf:

I've walked out of fewer than five movies in my entire life, and this was one of them. ....And here's the real problem... CGI is getting so realistic it's almost good enough to fool you into believing the animated characters are real people. WHY do we want to do this? Is there some hidden virtue getting to this point? ('Reviewer_D', 2007)

Considering the comments that lend support to the idea of eeriness arising from uncertainty in the viewer as to how to categorize these characters (category uncertainty theory), together with earlier ones suggesting it is the jarring nature of the eyes of characters which is the cause of eeriness (perceptual mismatch theory) suggests viewers may experience the uncanny nature of characters differently. In addition to visual and motion features described earlier, an inconsistency in Ray Winstone's voice for Beowulf was commented upon with one reviewer noting 'the film really suffers when he shouts in full cockney accent "I will kill you monstah [sic]!”' ('cdemw', 2007).

Regardless of the precise nature of their uncanniness, films featuring CGI- and Rotoshopped-Humans were capable of eliciting negative feelings in some viewers. In an earlier study, when shown selected excerpts featuring the protagonists in the films examined here, just over half of the participants reported experiencing at least one of the primary emotions of fear, happiness, surprise, anger, disgust or sadness (Hetherington, 2015). The emotional impact of a film is what may give it its appeal. Using fear as an example, Walton proposed that any emotions experienced during make-believing fictional truths in a fictional world are distinct from those experienced in reality, referring to them as 'quasi-emotions' (Walton, 1990). This contentious view ${ }^{6}$ brings to light the 'paradox of emotional response to fiction' that responding emotionally to fictional characters that do not exist is irrational yet highly familiar (Radford, 1975). Putting the nature of these emotions aside, it is indisputable that engagement in fictions can produce an affective response and one aspect of the viewing experience this argument reminds us of is the nature of the affective response from being involved in a work of fiction as opposed to when examining it with 'aesthetic distance' (Neill, 1991). Also, of possible relevance to this argument is the observation that similar patterns of brain activity can be observed in viewers when emotional avatar faces look highly similar to human faces, 
suggesting that at least under certain conditions the emotional response to real and digital humans can be similar when determined by neuroimaging (de Borst and de Gelder, 2015).

The difference in quality of social interaction between CGI- and Rotoshoppedhumans is an interesting finding from this study. Both forms of animation are characterised by the involvement of an actor in the character's performance. In the case of the CGI movies, character movement was predominantly created using mocap, whereby motion data from the body and face (if performance capture) is captured and abstracted from the performing actor and applied to a CGI model, which may or may not physically resemble the original actor. Animators are usually involved in this process, as the data often requires 'cleaning-up' and augmenting; or in some cases, character movement may need to be created which is physically impossible for the actor to achieve. In the case of $A$ Scanner Darkly the film was shot entirely as a live-action production. The film was then locked and handed over to the animators who used interpolated rotoscoping computer software (Rotoshop) to create the final animated film. Acting is a form of pretending, and clearly takes a very direct role in creating character performances in the films examined here. Walton makes the distinction between different types of prop in authorised versus unofficial games of make-believe. In authorised games, the function of the prop is to prescribe a very specific imagining. This would be the case for representations including animated films where the imaginings of the viewers are to be in accordance with the creator's intentions. In contrast, unofficial games of make-believe occur where the relationship between the prop and the imagining is less prescriptive (Walton, 1990). An example would be the function of a stick in children's make-believe play which could serve as a sword, machine-gun, magic wand, light sabre etc depending upon rules employed in the game. We suggest it is the form, availability and functioning of props available to actors in these movies that may assist in explaining the differences in audience perception of the social behaviours of these animated characters.

In A Scanner Darkly the referent used for rotoscoping was the live-action movie, which from the perspective of the actor meant that they had the entire range of makebelieve props to facilitate their imaginings of the fictional world their character was a part of including: costumes, props (as in the theatrical sense), other actors to act with, as well as being present on set and immersed in the story's environment. Knowing that the film was to be rotoscoped, the main actors when interviewed alluded to using exaggeration an established animation principle. This can be seen in the facial expression of 'Freck' played by Rory Cochrane (see Figure 2), with the Rotoshop technique also being capable of enhancing any gestures made by the actors (Ruddell, 2011). Woody Harrelson playing the Luckman character states he went a little more 'over the top' with his acting technique because he knew the film was going to be animated and Keanu Reeves described 'making a move a little bigger' at times (A Scanner Darkly, 2006b). This situation contrasts markedly with actors whose performance has been mocapped where many make-believe props were absent: instead of being in-costume with makeup, the actor has to wear a skin-tight suit with markers on it for capturing motion data and if facial data are required wearing a headset and facial markers; they are physically situated on a motion capture stage removed from the diegetic environment and often from the other actors involved in the scene thereby depriving them of any spontaneity and natural 
social interaction. So for example, rather than being able to establish eye contact naturally with another cast member, the actor may be required to fixate on some form of marker. Furthermore, a drawback of motion capture is the inability to capture accurate, context-sensitive eye movement (for example, saccades) which may also have contributed to observations of characters staring into space (see Figure 1); any eye movement has to be supplied by an animator in post-production. In Final Fantasy: The Spirits Within, Ming-Na, the actress who played Aki Ross the female protagonist, expressed her difficulty at not having another actor's performance to work off (Ryan, 2001). Acting knowledge and ability is also the province of the animator (Hooks, 2003) and in the case of the films examined here the animator adds a secondary performance offering an additional opportunity to modify a character's performance and its believability - a process which could preserve, augment or obscure the actor's original dramatic intention.

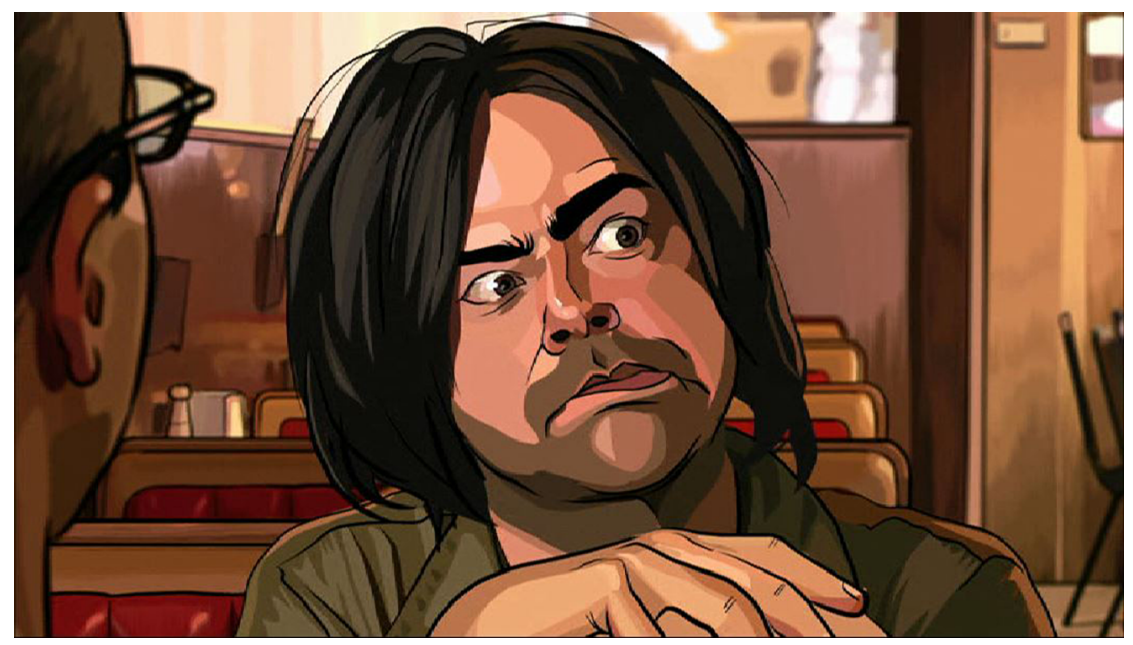

Figure 2. Exaggeration of facial expression in the 'Freck' character played by Rory Cochrane in A Scanner Darkly (2006). Screen grab from DVD [A Scanner Darkly, Richard Linklater].

\section{Conclusion and Discussion}

Wells points out a scarcity in studies of audience reception of animated films over 'particular historically determined periods' (Wells, 1998) prompting us to attempt a qualitative inquiry using online film review aggregator sites as a source of data for the present work. Moreover, the increasing importance and authority of online movie reviews written by 'non-critics' (McCarthy, 2007) and the potential consequences for a film's commercial success provides an added dimension to the value of such studies. The films chosen were characterised by their use of digital humans as animated characters created either by CGI techniques or using Bob Sabiston's Rotoshop software. In terms of CGI, the three films chosen (Final Fantasy: The Spirits Within, The Polar Express and Beowulf) represent a time span from 2001 to 2007 where many CGI and animation techniques were in a rapidly evolving phase of development contributing to the distinct aesthetic of these films. Contemporary to this was the release of $A$ Scanner Darkly, a film with it's own distinct realistic yet painterly aesthetic created by interpolated rotoscoping of a live-action film with Rotoshop. We also contend that these films have served as 
interesting examples to examine and apply Walton's Make-believe theory on engagement with representational artworks (Walton, 1990).

The present work has demonstrated that online reviewer aggregator sites can provide a rich source of phenomenological content that contributes to our understanding of the viewing experience/audience reception of the films examined. We were able to identify that a significant motivation to view a film was previous knowledge of its story or characters from another form of media such as a novel or videogame, and the anticipation of experiencing it in a different form of representation. The viewers' initial experience of the story often served as a benchmark from which to judge the film. For the CGI films, the nature of the viewing medium was also an important factor in motivating the viewer and providing them with an enhanced experience when displayed in $3 \mathrm{D}$, Imax or 3D-Imax format with suggestions of the viewing experience moving from that of 'looking at' to one of more 'being in' the story world. For some reviewers, the viewing medium appeared to be the more memorable part of the viewing experience with $3 \mathrm{D}$ or Imax technology offering the possibility of greater immersion into the diegetic world. The introduction of the 4DX film format may enable the experience to be further augmented through use of haptic and olfactory stimuli.

Our qualitative inquiry also highlighted the importance of taking account of individual differences in the viewing experience particularly in relation to the uncertain ontology of digital human characters. The eerie nature of CGI-Human characters and their falling into the uncanny valley has been commented upon previously (Aldred, 2011; Sobchack, 2006; Plantec, 2007; Hetherington, 2015; Kätsyri, Mäkäräinen, and Takala, 2017) and MacDorman and Entezari have reported individual differences in sensitivity to the uncanny valley (MacDorman and Entezari, 2015). Rotoshopped-Humans perceived to be eerie have also been reported in the literature (Ward, 2004; Hetherington, 2015), but we were unable to find supporting evidence of this from online reviews. The basis of the uncanniness may be related to the presence of an atypical feature of the character such as the eyes in CGI-Humans or the movement of visual elements on the face in RotoshoppedHumans, both of which favour the perceptual mismatch hypothesis (Kätsyri et al, 2015). Another interesting finding from this study was how character perceptions became more problematic when there was familiarity of the actor playing the CGI character in Beowulf. In this case we propose that a different form of eeriness is operating where the viewer experiences difficulty in categorising the character as a complete entity (category uncertainty hypothesis); for one viewer this was enough for them to abandon their engagement with the fictional world. We found reviews ranging from an inability to distinguish CGI-Human characters from real humans; observations of characters fleetingly exhibiting realism before returning to their artifice and cases of characters being viewed as eerie. Such observations illustrate the complexity and the dynamic nature of this phenomenon. We also encountered examples of reviewers abandoning their viewing of Beowulf, The Polar Express or A Scanner Darkly due to boredom. In the case of the latter, the breakout from make-believe appeared to be caused by difficulties with comprehending the story. In other instances, reviews didn't identify the cause of boredom meriting further work to identify causation. 
In addition to confusing and inconsistent individual character traits, CGI-Human character performances were often characterised by inappropriate or misunderstood social interaction. Examples included characters not maintaining eye contact with each other in Beowulf and a confused kiss in Final Fantasy: The Spirits Within. We suggest the lack of appropriate social interaction between characters could be due to the limitations and nature of the motion capture process where the actor is deprived of makebelieve 'props' which prescribe specific imaginings assisting the actor in their performance (or game of make-believe). No reviews were found describing inappropriate social interaction between characters for Rotoshopped-Humans. Furthermore, comments frequently identified and praised the 'chemistry' between the actors, with some speculating that the technique had enhanced the performance in some instances. Rotoshop uses a live-action movie as its referent with the actors having access to all the necessary make-believe props to facilitate their imaginings of the fictional world (costumes, makeup, presence of other actors, mise en scène). Moreover, the use of this technique in A Scanner Darkly appears to have conserved the performances captured in live-action. Reviews consistently referenced performances in relation to the actors involved and didn't reveal any evidence of the confusion in actor-character identity found with the CGI-Humans.

Carruthers (2002) argues that adult creative thinking and problem solving draw upon the same cognitive resources as those utilised in childhood pretend play and that the role of childhood pretending is to practice and enhance adult forms of creativity. In animation practice, scripts, storyboards and concept artwork serve as make-believe props aiding the imagination in understanding and considering the proposed fictional world. Acting also has an association with make-believe and Hooks (2003) asserts that it isn't enough to make a character move in a believable way unless they are animated with theatrical intention and purpose ${ }^{7}$. Actors and animators tend to acquire their acting skills differently: Actors work in the present, responding to each other and the audience through workshops and performance. While animators learn acting largely through observation and discussion creating a single character performance in their mind (Hooks, 2003). The films examined here serve as an interesting selection of case studies for examining the influence of actor versus animator on a character's performance and believability. Ideas from animation and drama have served as inspiration in artificial intelligence (AI) where the goal has been the creation of believable embodied agents and humanlike robots that offer the possibility of natural interaction between human and machine. In this context, consistency in narrative, verbal and non-verbal behaviour, and sociocultural context is seen as central to achieving believability (Simmons et al, 2011). The abstract nature of believability has led Gomes et al (2013) to propose a number of dimensions of believability for characters in interactive narratives including: visual impact, coherence and understandability of behaviour, personality (covering details of behaviour, thought and emotion), emotional expressiveness and social competence. These dimensions have been repurposed into metrics, some of which could be applicable in identifying relevant traits of animated characters in audience reception studies.

In relation to narrative, we found a few cases of abandonment of the animated fictional world (e.g. A Scanner Darkly) or disappointment in the representation of the narrative by the movie (e.g. Final Fantasy: The Spirits Within, Beowulf and The Polar 
Express). Previous experience of a narrative is what Walton refers to as 'background propositions' (Walton, 1990) which are imported by viewers to extend the content provided and reveals a schematic nature to make-believe. Schemata can be manifest as genres, recurrent plot devices (tropes) and various background assumptions or propositions (Turner et al, 2015). However, in this situation rather than augment the experience, conflict has resulted where the new information garnered from the movie does not fit the viewer's existing schema. When this happens a common reaction is rejection, or to quickly forget the new information (Taylor and Crocker, 1981). It seems likely that accommodating any existing schema, or creating a new one to address any inconsistencies that have arisen (restructuring), requires effort and it is tempting to relate this to Wells' observation of there being an essential 'tension' between belief and disbelief in the experience of viewing an animated film (Wells, 1998). Work by Gerrig and colleagues relating to the cognitive psychology of engagement in literary fictional worlds may also be of relevance in this respect. Gerrig and Egidi suggest cognitive processing of written fictional texts occurs on a continuum with intuitive processes dominating at one end and reflective processes at the other. Intuitive processes are rapid and effortless, while reflective processes are deliberate, slow and effortful. Individual readers may occupy different positions on that continuum and may move along it depending upon the details of the story (Gerrig and Egidi, 2010). The amount of cognitive effort required is important in determining the ease of transport into the fictional world, the less effort required the greater the chance of engaging and remaining engaged in that fictional world. A number of studies have revealed that narrative experiences are predominantly guided by intuitive processes and that readers more easily believe rather than disbelieve fictions as less cognitive effort is required (Prentice and Gerrig, 1998; Gerrig and Rapp, 2004). Importantly, Gerrig and Rapp (2004) propose this situation to be generalisable to any fictional narrative.

The discussion above prompts a re-evaluation of Samuel Taylor Coleridge's 'willing suspension of disbelief' (Coleridge, 1817/1907) which has been generalised to describe our engagement in all fictional worlds. The term seems often clichéd in its use and implies that our default state when approaching fiction is disbelief that must somehow be overcome to enable transportation into a fictional world. However, the work of Gerrig and colleagues reveals a different situation - it is much less effort cognitively to adopt a state of belief as the default state as disbelief must actively be constructed (Gerrig and Egidi, 2010; Gerrig and Rapp, 2004). Given the capacity of animation to create engaging, vivid and believable fictional worlds; the use of display technologies that have the potential to offer more immersive experiences for the viewer; and the pervasive nature of make-believe as a critical part of our development from child into adult, perhaps the notion of a state of belief rather than disbelief as the starting point for engaging with animated fictional worlds isn't so surprising?

\section{Acknowledgements}

We would like to acknowledge Caroline Ruddell, Suzanne Buchan, Chris Atton and the anonymous reviewers for their helpful advice during the writing of this article. We also thank the Internet Movie Database (www.imdb.com), Rotten Tomatoes 
(www.rottentomatoes.com) and Metacritic (www.metecritic.com) for permission to quote user reviews. Part of this research was completed with the award of a university research internship to Rachel McRae.

\section{Funding}

This research received no specific grant from any funding agency in the public, commercial, or not-for-profit sectors.

\section{Notes}

1. Mori's original article became popular after its translation from the original Japanese. In earlier versions the Uncanny Valley was shown graphically as the relationship between human likeness (x-axis) and familiarity (y-axis). However, upon re-examination it is now believed that Mori's intended meaning relates to affinity rather than familiarity. A complete description of the relationship can be found in MacDorman and Entezari (2015).

2. Bracketing or epoche is applied in phenomenological-based qualitative research in order to alleviate any potentially damaging effects of preconceptions that may devalue the research undertaken.

3. Walton's consideration of make-believe is a relatively rare example of its application to adult cognition. The treatment of pretending in psychology is largely confined to its role in childhood where it has been implicated in social, affective and cognitive development.

4. A comprehensive discussion of the uncanny valley and related writings on the uncanny is beyond the scope of this article. Royle (2003) provides a historical account of critical and cultural theory relating to the uncanny, and more recently Tinwell has examined the uncanny valley theory in games and animation (Tinwell, 2014). A recent review of empirical studies on the uncanny valley has been conducted by Kätsyri et al. (2015).

5. Dick PK (1977) A Scanner Darkly. London: Gollancz.

6. The view expressed by Walton (1990) that make-believing fictional worlds can lead to the generation of quasi-emotions has been refuted. Noel Carroll (1987) for example, questions the accuracy of Walton's description maintaining that an authentic rather than quasi-emotional state exists when we are moved by a work of fiction. Alex Neill's article gives a succinct analysis and criticism of the 'fear scenario' offered by Walton in support of quasi-emotions (Neill, 1991).

7. An example of the conscious effort made to create believability in animated cartoons comes from the work of Disney Studios during the golden age of American animation (Thomas and Johnston, 1981) and is discussed in relation to pretending in Turner et al (2015). 


\section{References}

'AaronN' (2007). Beowulf. Available at: http://www.rottentomatoes.com/user/id/185584554/\# (accessed 7 April 2016).

Aldred J (2011) From Synthespian to Avatar: Re-framing the Digital Human in Final Fantasy and The Polar Express. Available at: http://www.tft.ucla.edu/mediascape/Winter2011_Avatar.pdf (accessed May 5 2016).

Atton C (2012) Listening to 'difficult albums': specialist music fans and the popular avant-garde. Popular Music, 31: 347-361.

A Scanner Darkly (2006a) [film] USA: Richard Linklater.

A Scanner Darkly (2006b) The Weight of the Line: Animation Tales. [DVD] USA: Richard Linklater.

'awjonesjr' (2001) You can't replace acting with CGI, but you can try. Available at: http://www.imdb.com/title/tt0173840/reviews-67 (accessed 1 April 2016).

Banks J (2015) Object, Me, Symbiote, Other: A social typology of player-avatar relationships. First Monday, 20(2). Available at: http:/firstmonday.org/ojs/index.php/fm/article/view/5433/4208 (accessed 12 May 2016)

Bateman C (2010) Game Design as Make-Believe. Available at: http://blog.ihobo.com/2010/05/game-design-as-makebelieve.html (accessed 21 November 2016)

Bateman C (2011) Imaginary Games Winchester, UK: Zero Books.

Beowulf (2007) [film] USA: Robert Zemeckis. 
Bestor N (2016) The Technologically Determined Decade: Robert Zemeckis, Andy Serkis and the Promotion of Performance Capture. animation: an interdisciplinary journal 11(2): 169-188.

Carroll N (1987) The Nature of Horror. Journal of Aesthetics and Art Criticism 46(1): 51-59.

Carruthers P (2002) Human Creativity: Its Cognitive Basis, its Evolution, and its Connections with Childhood Pretence. Brit. J. Phil. Sci. 53: 225-249.

'cdemw' (2007) Surprisingly good - a 3D treat. Available at: http://www.imdb.com/title/tt0442933/reviews?start=0 (accessed 26 April 2016)

Chakravarty A, Liu Y, and Mazumdar T (2010) The Differential Effects of Online Wordof-Mouth and Critics' Reviews on Pre-release Movie Evaluation. Journal of Interactive Marketing 24: 185-197.

'cinderellakt' (2008) A travesty. Available at: http://www.imdb.com/title/tt0442933/reviews-440?mode=desktop $\quad$ (accessed 26 April 2016)

Coleridge ST (1907) Biographia Litereria. Oxford: Oxford University Press (Originally published in 1817)

Cresswell JW (2013) Qualitative Inquiry and Research Design. 3rd ed. London: Sage Publications

'crowrobot' (2005) Visually stunning and exciting animated epic. Available at: http://www.imdb.com/title/tt0173840/reviews-743 (accessed 30 March 2016).

de Borst AW, de Gelder B (2015). Is it the real deal? Perceptions of virtual characters versus humans: an affective cognitive neuroscience perspective. Front. Psychol. 6:576. doi: 10.3389/fpsyg.2015.00576 
De Jong IKE, Burgers C (2013) Do consumer critics write differently from professional critics? A genre analysis of online film reviews. Discourse, Context and Media, 2: 75-83.

'Dribbleglass' (2007) Pleasantly surprised. Available at: http://www.imdb.com/title/tt0405296/reviews-210 (accessed 30 March 2016).

Ebert R (2001) Final Fantasy: The Spirits Within. Available at: http://www.rogerebert.com/reviews/final-fantasy-the-spirits-within-2001 (accessed 28th November 2016).

Elliot, AJ, Devine, PG (1994). On the motivational nature of cognitive dissonance: Dissonance as psychological discomfort. Journal of Personality and Social Psychology 67(3): 382-394.

'Eternality' (2011) Beowulf can be described as a colossal disappointment. Available at: http://www.imdb.com/title/tt0442933/reviews-515 (accessed 17 March 2016).

Festinger L (1957) A Theory of Cognitive Dissonance. Stanford, CA: Stanford University Press.

Final Fantasy: The Spirits Within (2001) [film] USA: Hironobu Sakaguchi.

Flatblackfilms.com (n.d.) Rotoshop. Available at: http://www.flatblackfilms.com/Flat_Black_Films/Rotoshop.html (accessed 9 May 2016).

Follows S (2014) Do film critics and film audiences agree? Available at: https://stephenfollows.com/do-film-critics-and-audiences-agree/ (accessed 6 May 2016).

'FranzH' (2015) Beowulf. Available at: http://www.rottentomatoes.com/user/id/971664638/ratings (accessed 30 March 2016). 
Freud S (2003) The Uncanny. (D. McLintock, Trans.) London: Penguin Classics. (Originally published in 1919).

Gomes P, Paiva A, Martinho C, Jhala A (2013) Metrics for Character Believability in Interactive Narrative. In: H. Koenitz et al. (Eds): ICIDS 2013, LNCS 8230, pp. 223228.

Gerrig RJ, Rapp, DN (2004). Psychological Processes Underlying Literary Impact. Poetics Today 25:2 (Summer 2004), pp. 265-281.

Gerrig RJ, Egidi G (2010) The Bushwacked Piano and the Bushwacked Reader: The Willing Construction of Disbelief. Style 44, Nos. 1 \& 2, Spring/Summer 2010, pp 189-206.

Hetherington R (2015) The Believability of Hyper Realistic Characters in Animated Movies. In: MIDI '15 Multimedia, Interaction, Design and Innovation. Warsaw: ACM Digital Library. Available at: http://dl.acm.org/citation.cfm?id=2814478 (accessed 9 May 2016).

Honess Roe A (2011) Uncanny Indexes: Rotoshopped Interviews as Documentary. animation: an interdisciplinary journal 7(1): 25-37.

Hooks E (2003) Acting for Animators. Portsmouth: Heinemann.

IMDb (2016) Press Room. Available at: http://www.imdb.com/pressroom/about/ (accessed 6 May 2016).

'jaredmobarak' (2007) Sins of the father....Beowulf. Available at: http://www.imdb.com/title/tt0442933/reviews-143 (accessed 18 March 2016).

Jentsch E. (1997) On the Psychology of the Uncanny. (R. Sellars, Trans.) Angelaki 2(1): 7-16. (Originally published in 1906). 
'jluis 1984' (2007) A great retelling of a legend. Available at: http://showtime.imdb.com/user/ur4939636/comments-expanded?order $=$ date\&start $=0$ (accessed 30 March 2016).

'joltjohn' (2002) An out of this world visual and sound experience. Available at: http://www.imdb.com/user/ur2017521/comments-expanded?start=10\&order=alpha (accessed 6 May 2016).

Kätsyri J, Förger K, Mäkäräinen M, and Takala T (2015). A review of empirical evidence on different uncanny valley hypotheses: Support for perceptual mismatch as one road to the valley of eeriness. Frontiers in Psychology, 6(390): 1-16.

Kätsyri J, Mäkäräinen M, and Takala T (2017) Testing the 'uncanny valley’ hypothesis in semirealistic computer-animated film characters. An empirical evaluation of natural film stimuli. International Journal of Human Computer Studies 97: 149-161.

Landis J and Koch G (1977) The Measurement of Observer Agreement for Categorical Data. Biometrics, 33(1): 159-174.

'legendarydrunkenmaster' (2009) One of the best PKD adaptations. Available at: http://www.imdb.com/user/ur16267787/ (accessed 30 March 2016).

MacDorman KF, Green RD, Ho C-C, Koch KT (2009) Too real for comfort? Uncanny responses to computer generated faces. Computers in Human Behavior 25: 695-710.

MacDorman KF and Entezari S (2015) Individual differences predict sensitivity to the uncanny valley. Interaction Studies, 16(2): 141-172.

Mangan B (2015) The uncanny valley as fringe experience. Interaction Studies 16(2): 193-199.

Mar RA, Kelley, WM, Heatherton, TF and Macrae CN (2007) Detecting agency from the biological motion of veridical vs animated agents. SCAN 2: 199-205. 
'Mary P' (2014) Beowulf reviews. Available at: http://www.rottentomatoes.com/m/beowulf/reviews/?page=4\&type=user $($ accessed 1 April 2016).

Materna M (2006) 'A Scanner Darkly': An Animated Illusion. Animation World Network. Available at: http://www.awn.com/animationworld/scanner-darkly-animated-illusion (accessed 9 May 2016).

McCarthy T (2007) Crix mix needs fix: reviewers get feisty as consumer media trims coverage and online voices grow louder. Variety 408(9): 1.

McClean ST (2007) Digital Storytelling: the narrative power of visual effects in film. London: MIT Press.

Mori M (1970) Bukimi no tani (the uncanny valley). Energy 7: 33-356. (MacDorman, KF and Minato, T Trans. In 2005 for the paper Androids as an Experimental Apparatus: Why there is an uncanny and can we exploit it? In: Proceedings of the CogSci 2005 Workshop: Toward Social Mechanisms of Android Science. Italy, July 2005, 106118).

'Neil Welch' (2009) Good but weird. Available at: http://www.imdb.com/title/tt0442933/reviews?filter=love;filter=love;start=70 (accessed 30 March 2016).

Neill, A (1991) Fear, Fiction and Make-Believe. The Journal of Aesthetics and Art Criticism 49(1): 47-56.

Plantec P (2007) Crossing the Great Uncanny Valley. Available at: http://www.awn.com/vfxworld/crossing-great-uncanny-valley (accessed April 22 2016).

Prentice DA, Gerrig RJ (1998). Exploring the Boundary between Fiction and Reality. In: S. Chaiken \& Y. Trope (Eds.), Dual-process theories in Social Psychology. New York: Guilford, pp. 529-546. 
Prince S (1996) True Lies: Perceptual Realism, Digital Images, and Film Theory. Film Quarterly 49(3): 27-37.

Quantcast.com. (2016) Rottentomatoes.com Traffic and Demographic Statistics by Quantcast. Available at: https://www.quantcast.com/rottentomatoes.com (accessed 6 May 2016).

Radford C (1975) "How Can We Be Moved by the Fate of Anna Karenina?" Proceedings of the Aristotelian Society, Supplemental Vol. 49, pp. 67-80.

'Reviewer_A' (2011). A Scanner Darkly. Available at: http://www.metacritic.com/user/AFountain (accessed 5 April 2016).

'Reviewer_B' (2001). Final Fantasy: The Spirits Within. Available at: http://www.metacritic.com/movie/final-fantasy-the-spirits-within/user-reviews (accessed 1st April 2016).

'Reviewer_C' (2001) Final Fantasy: The Spirits Within. Available at: http://www.metacritic.com/movie/final-fantasy-the-spirits-within/user-reviews (accessed 1 April, 2016).

'Reviewer_D' (2007) Beowulf. Available at: http://www.metacritic.com/movie/beowulf/user-reviews (accessed 1 April 2016).

'Robert D' (2009) Beowulf. Available at: http://www.rottentomatoes.com/user/id/901244398/ (accessed 18 March 2016).

Royle N (2003) The uncanny. Manchester: Manchester University Press.

Ruddell C (2011) 'Don't Box Me In': Blurred Lines in Waking Life and A Scanner Darkly. animation: an interdisciplinary journal 7(1): 7-23. 
Ryan T (2001) Fantasy Girl's a Geek. Available at: http://web.archive.org/web/20120324052710/http://archives.starbulletin.com/2001/0 7/10/features/story1.html (accessed 12 April 2016).

Simmons R, Makatchev M, Kirby R, Lee MK, Fanaswala I, Browning B, Forlizzi J and Sakr M (2011). Believable Robot Characters. AI Magazine, winter 2011: 39-52.

Sobchack V (2006) Final Fantasies: Computer Graphic Animation and the [Dis] illusion of Life. In: Buchan S (ed.) Animated Worlds. Eastleigh: John Libbey, pp.171-182.

Taylor, S. E., \& Crocker, J. (1981). Schematic bases of social information processing. In E. T. Higgins, C. A. Herman, \& M. P. Zanna (Eds.), Social Cognition: The Ontario Symposium on Personality and Social Psychology Hillsdale, NJ: Erlbaum, pp. 89134.

'The_Amazing_Spy_Rises' (2007) A legendary story suffers a legendary butchering. Available at: http://www.imdb.com/title/tt0442933/reviews-82 (accessed 7 April 2016)

The Polar Express (2004) [film] USA: Robert Zemeckis.

'theshadow908' (2006) Terrible. The book is much better. Available at: http://www.imdb.com/title/tt0338348/reviews?start=420 (accessed 1 April 2016).

Thomas F, Johnston O (1981) The Illusion of Life. New York: Disney Editions.

Tinwell A (2014) The Uncanny Valley in Games and Animation. Boca Raton: CRC Press

Trafficestimate.com (2016) metacritic.com Website Traffic and Information | TrafficEstimate.com. Available at: http://www.trafficestimate.com/metacritic.com (accessed 6 May 2016).

Turner P, Hetherington R, Turner S and Kosek M (2015) The limits of pretending. Digital Creativity, DOI: 10.1080/14626268.2015.1091778 
Waking Life (2001) [film] USA: Richard Linklater.

Ward P (2004) Rotoshop in context: computer rotoscoping and animation aesthetics. Animation Journal 12:32-52.

Ward P (2011) Independent Animation, Rotoshop and Communities of Practice: As seen through A Scanner Darkly. animation: an interdisciplinary journal 7(1): 59-72.

Walton K (1990) Mimesis as Make-Believe: On the Foundations of the Representational Arts. Cambridge, Massachusetts: Harvard University Press.

Wells P (1998) Understanding Animation. London: Routledge. 